https://doi.org/10.15407/ujpe63.6.521

V.E. CHECHKO, ${ }^{1,2}$ V.YA. GOTSULSKYI ${ }^{3}$

${ }^{1}$ I.I. Mechnikov National University of Odessa, Chair of Theoretical Physics and Astronomy

(42, Pasteur Str., Odessa 65082, Ukraine; e-mail: AstandPPWT@ukr.net)

2 I.I. Mechnikov National University of Odessa, Scientific and Research Institute of Physics

(27, Pasteur Str., Odessa 65082, Ukraine)

${ }^{3}$ I.I. Mechnikov National University of Odessa, Chair of General and Chemical Physics

(2, Dvoryanskaya Str., Odessa 65000, Ukraine; e-mail: vygot@onu.edu.ua)

\title{
QUALITATIVE ANALYSIS
}

OF CLUSTERING IN AQUEOUS ALCOHOL SOLUTIONS

\begin{abstract}
The specific features of clustering in the aqueous solutions of monohydric alcohols with concentrations higher than that at the peculiar point are discussed. Clustering is a result of the formation of hydrogen bonds between water and alcohol molecules, the energy of which somewhat exceeds the energy of hydrogen bonds in the water-water and alcohol-alcohol molecular pairs. Elementary clusters are assumed to be formed, whose composition is fixed at the solution concentrations lower than that at the peculiar point and changes according to a certain law at higher concentrations. The solution clustering degree was determined as a function of the solution concentration and the temperature.

Ke ywords: solutions, water, monohydric alcohols, elementary clusters, peculiar point.
\end{abstract}

\section{Introduction}

The properties of aqueous monohydric alcohol solutions differ substantially from the properties of ideal solutions [1-3]. This difference reveals itself in the optical properties of solutions, in particular, in the appearance of maxima in the abnormal light scattering [4-6], in the form of the concentration and temperature dependences of the adiabatic compressibility [7] and the heat capacity [8], in the emergence of large relaxation times $[2,9]$ and other features in the volumetric behavior of those solutions $[10,11]$, in particular, their contraction [12-14].

The first models of solutions as associated systems were developed by D.I. Mendeleev more than 150 years ago after the systematic studies of clustering in water-alcohol solutions [15]. This concept was developed and detailed in further researches, both experimental and theoretical ones, which had been reflected in a number of reviews $[1,16]$. In particular, Scatchard [17], using thermodynamic methods, studied the volume change at the solution formation from its components.

In works [12-14], the manifestation of clustering in the behavior of the simplest solution characteristic,

(c) V.E. CHECHKO, V.YA. GOTSULSKYI, 2018

ISSN 2071-0194. Ukr. J. Phys. 2018. Vol. 63, No. 6 its contraction, was examined. It was shown that the concentration dependences of the contraction in the aqueous solutions of methanol and ethanol measured at various temperatures intersect one another at the mole fractions $x_{p}=0.16$ and 0.077 , respectively. This point was called a peculiar point of solutions. Earlier, in works $[4,5]$, it was shown that there is a maximum of the abnormal light scattering in a vicinity of this point. The origin of this phenomenon still remains a challenging task.

It should be emphasized that the properties of water, in particular, the network of hydrogen bonds, play an important role at low solution concentrations. At low concentrations of alcohol, the solution remains locally homogeneous, and the following assumptions concerning its molecular structure can be made: it can be considered as an ideal ternary solution of elementary clusters and unclustered ethanol and water molecules. An elementary cluster includes two ethanol molecules with oppositely directed dipole moments, with each of the molecule being surrounded with a monolayer consisting of 13 water molecules, on the average [13]. This is the number of ethanol molecules that can satisfy an additional requirement that the dipole moment of the elementary cluster should equal zero. 


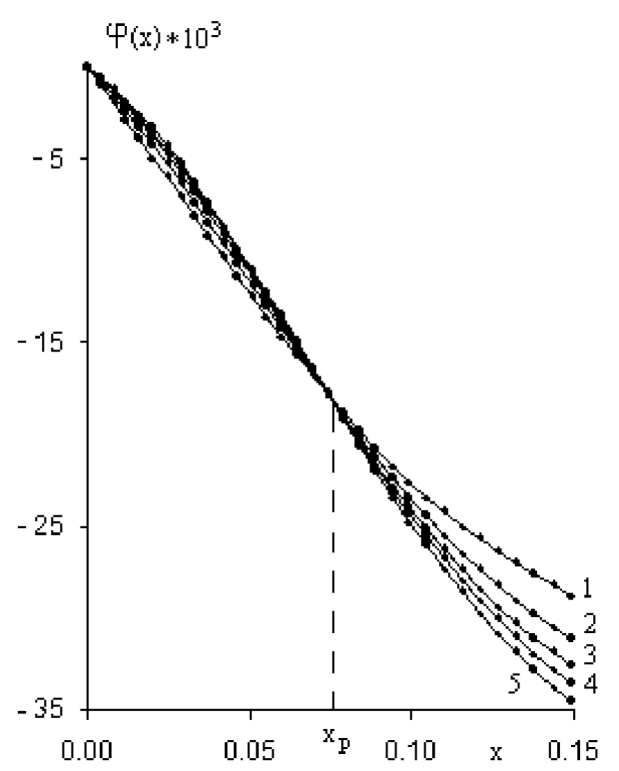

Fig. 1. Concentration dependences of the contraction of aqueous ethanol solutions in a vicinity of the peculiar point at various temperatures: 0 (1), 10 (2), 20 (3), 30 (4), and $40{ }^{\circ} \mathrm{C}(5)$. Experimental data were taken from work [24]. The dashed line marks the concentration at the peculiar point

Furthermore, at a certain concentration, the elementary clusters can form an infinite percolation cluster [18]. The clustering takes place at a concentration corresponding to the intersection of the contraction curves [12-14] and at the abnormal increase of the molecular light scattering intensity [4-6]. The latter phenomenon is closely associated with the fact that, from the thermodynamic viewpoint, the distribution of water molecules only in monolayers does not correspond to the entropy maximum, which results in the solution instability. The intersection point of the contraction curves defines the so-called peculiar point of the solution [12-14] (Fig. 1).

No less interesting are the solution concentration intervals located symmetrically with respect to the peculiar point in the diagram of states; i.e. solutions with a low water content. Unfortunately, this issue was left beyond the scope of interests of researchers. It should be noted that, unlike water molecules, alcohol molecules can create only chain or cyclic structures $[18,19]$. The emergence of linked cyclic formations is also possible. Here, we mean that some of linear chains can close on themselves to form loop-like structures. Some of them can be linked with one another. This circumstance may favor the forma- tion of a spatial network of hydrogen bonds, even in alcohols, which is ignored in many works. From whence, it follows that the nature of the clustering in this concentration region should differ from what is observed at low water concentrations.

It should be noted that the experimental data on the contraction and molecular light scattering testify that, to the left from the peculiar point in the water-alcohol solutions containing enough water molecules, only elementary clusters of the same type are formed. These are the clusters that manifest themselves in the emergence of the peculiar point of a solution. To the right from the peculiar point, the concentration dependence of the contraction reveals no specific features. Such a behavior is typical of ordinary molecular solutions (see work [19]). Therefore, we assume that the most stable clusters, which are formed to the right from the peculiar point, are structurally similar to elementary clusters existing at the peculiar point. For the solution in those states, the system can be considered as an ideal ternary solution of alcohol, elementary clusters, and unclustered water.

Note that, in the works by Mendeleev [15], it was considered that there may exist a few types of clusters (associates). However, the lack of a fine structure in the concentration dependences of the contraction forces us to conclude that there exist only elementary clusters, whose composition changes continuously, as the concentration increases. It should be emphasized that clusters are short-lived entities, because the lifetime of hydrogen bonds is limited [20-22]. In the analysis given below, the special attention will be paid only to the influence of the clustering on a solution volume change as a result of the formation of elementary clusters. We emphasize that no detailed assumptions are made about the specific spatial structure of the solution. The main aim of our work consists in describing the clustering degree of the aqueous solutions of monohydric alcohols with a low water content. For this purpose, an expression is presented below for the density of solutions obtained under the assumptions described above.

\section{Model of the Properties of Water-Alcohol Clusters}

According to our assumptions, the solution consists of three components: unclustered water and alcohol 
molecules and elementary clusters. As a result, the total solution volume is modeled to be equal to the sum of the unclustered water, $V_{w}^{(n c)}$, and alcohol, $V_{a}^{(n c)}$, volumes and the volume occupied by the elementary clusters, $V_{w a}^{(c)}$ :

$V_{s}=V_{w}^{(n c)}+V_{a}^{(n c)}+V_{w a}^{(c)}$.

An elementary cluster is assumed to include both water and alcohol molecules. The cluster composition is characterized by the parameter $k=z_{w} / z_{a}$, where $z_{w}$ and $z_{a}$ are the numbers of water and alcohol, respectively, molecules composing the cluster. If $N_{w}$ water molecules are added to alcohol, some part of them, $Z_{w}$, become clustered. As a result, the volume occupied by unclustered alcohol molecules equals

$V_{w a}^{(n c)}=V_{a}^{(0)}-v_{a} Z_{w} N_{w} \frac{1}{k}$,

where $V_{a}^{(0)}=v_{a} N_{a}$ is the initial alcohol volume, $v_{a}=$ $m_{a} / \rho_{a}$ is the volume per alcohol molecule in pure alcohol $\left(m_{a}\right.$ is the molecular weight of alcohol, and $\rho_{a}$ is the alcohol density), and $N_{a}$ is the number of alcohol molecules.

Note that the degree of solution clustering can also be determined in the framework of the chemical equilibrium theory [23]. In this case, however, one should know the magnitude of the system energy change at the formation of an elementary cluster. This issue will be considered in a separate work.

The volume of water that is not included into the cluster is determined by the expression

$V_{w}^{(n c)}=\left(1-Z_{w}\right) v_{w} N_{w}$,

where $v_{w}=m_{w} / \rho_{w}, m_{w}$ is the molecular mass of water, and $\rho_{w}$ its density. If the solution is completely clustered - this is the case at the peculiar point - its volume is determined by the total mass of the water and alcohol molecules that form elementary clusters and the density of the totally clustered solution,

$V_{w a}^{(c)}=\frac{m_{w}+\frac{m_{a}}{k}}{\rho_{c}}=\frac{k m_{w}+m_{a}}{\rho_{c}} \frac{1}{k} N_{w}=v_{c} \frac{1}{k} N_{w}$,

where $v_{c}$ is the volume of the clustered solution per one alcohol molecule or $k$ water molecules. From whence, as a consequence, we obtain

$v_{c}=\frac{k m_{w}+m_{a}}{\rho_{c}}$,

ISSN 2071-0194. Ukr. J. Phys. 2018. Vol. 63, No. 6 where $\rho_{c}$ is an experimentally measurable quantity. Then the total volume of the clustered component is determined as follows:

$V_{w a}^{(c)}=v_{c} \frac{1}{k} Z_{w} N_{w}$.

Ultimately, Eqs. (1)-(3) and (5) imply that the total volume of the solution is described by the expression

$V_{s}=\left(v_{a}-v_{a} Z_{w} \frac{1}{k}(1-x)+\right.$

$\left.+v_{w}\left(1-Z_{w}\right)(1-x)+v_{c} Z_{w}(1-x) \frac{1}{k} N_{w}\right) N$,

and its density, which can be determined experimentally, is equal to

$\rho_{c}=\frac{\left(m_{w}(1-x)+m_{a} x\right) N}{V_{s}}$,

where $N=N_{a}+N_{w}$. If the solution concentration is equal to that at the peculiar point, $x=x_{p}$, the solution itself, according to our assumption, is completely clustered, i.e. $Z_{w}=1$ and $\rho_{s}(x)=\rho$. Therefore, the concentration at the peculiar point is related to the parameter $k$ by the equality

$1-x_{p}=k x_{p}$.

The latter gives rise to the obvious relation for $k$,

$k=\frac{1-x_{p}}{x_{p}}$,

which characterizes the composition of an elementary cluster at the peculiar point. This parameter remains the same to the left from the peculiar point. To the right from the peculiar point, where there is a deficiency of water molecules, we assume that the parameter $k$ is described by the formula

$k(x)=\frac{1-x}{x}$.

It continuously transforms into Eq. (9) when approaching the peculiar point (see Introduction). Proceeding from Eqs. (4) and (7), we can express the clustering degree of water molecules in the solution as a function of the molar fraction of alcohol in the form

$Z_{w}=\frac{k(x)}{(1-x)} \frac{v_{s}-v_{w}(1-x)-v_{a} x}{v_{c}-v_{a}-k(x) v_{w}}$,

where

$v_{s}=\frac{m_{w}(1-x)+m_{a} x}{\rho_{s}}$. 


\section{Clustering Degree of Aqueous Ethanol Solution}

The concentration dependences of the clustering degree of water molecules, $Z_{w}(x, T)$, in the solution of water in ethanol at various temperatures, which

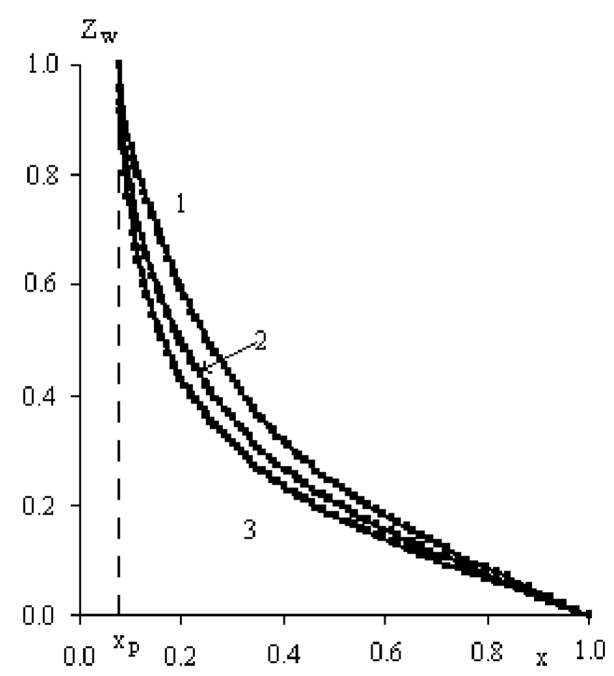

Fig. 2. Concentration dependences of the clustering degree of water molecules in the ethanol-water solutions at various temperatures: $0(1), 20$ (2), and $40{ }^{\circ} \mathrm{C}$ (3). Experimental data were taken from work [25]. The dashed line marks the concentration at the peculiar point

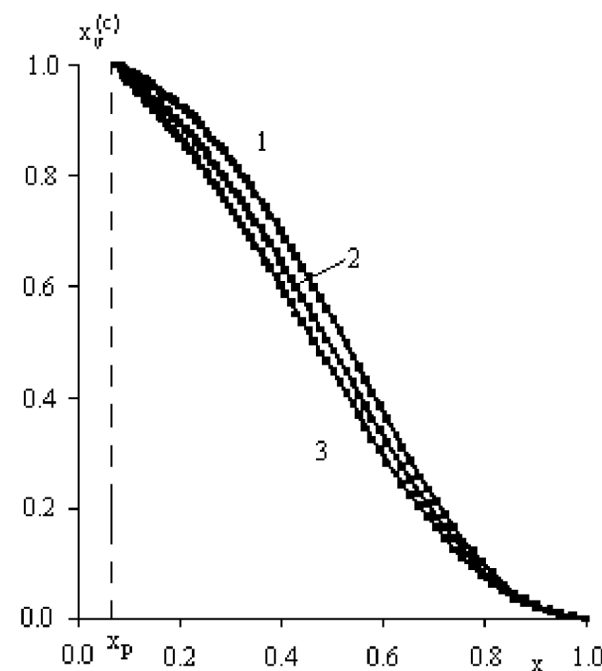

Fig. 3. Concentration dependences of the volume fraction of clusters in the ethanol-water solutions at various temperatures: 0 (1), 20 (2), and $40{ }^{\circ} \mathrm{C}$ (3). Experimental data were taken from work [24]. The dashed line marks the concentration at the peculiar point were calculated according to Eq. (10), are shown in Fig. 2. From the exhibited data, it is evident that the clustering degree of water molecules monotonically decreases as the temperature increases.

\section{Discussion of the Results Obtained}

In order to discuss the results obtained, some considerations are to be taken into account. Our main assumption consists in that the water-alcohol solution with a low water content can be regarded as a three-component one. The components of this solution are: alcohol, water, and the clustered solution component. The very fact of the appearance of clusters in the solutions of water and alcohols is one of the main differences between the solutions concerned and the ideal two-component solutions. It should be noted that clusters are formed in the solutions with any concentration.

In the solutions with a low water content, two competing tendencies are observed at the molecular level: $1)$ the alcohol molecules try to create elementary clusters with the water molecules, because their mutual interaction is stronger $[25,26]$; and 2) the composition of clusters changes due to the insufficient number of water molecules. As a result, there emerge clusters that are similar to elementary clusters, but

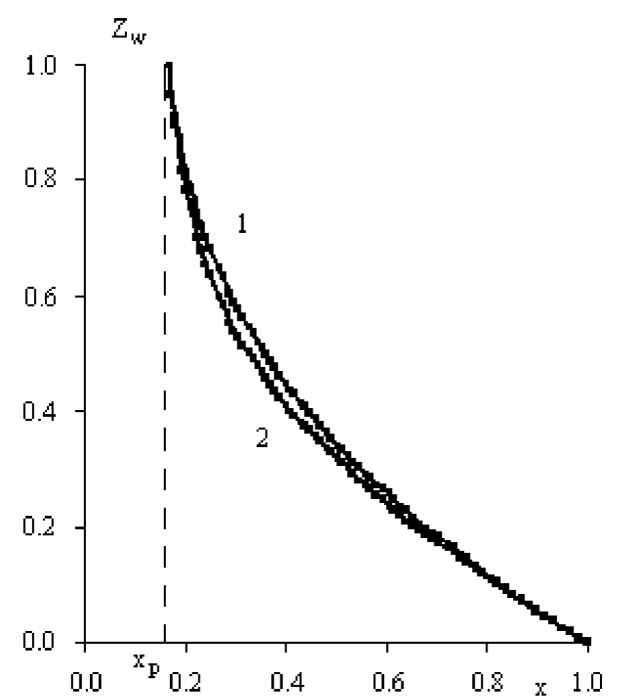

Fig. 4. Concentration dependences of the clustering degree of the water-methanol solutions at various temperatures: 0 (1) and $20{ }^{\circ} \mathrm{C}$ (2). Experimental data were taken from work [27]. The dashed line marks the concentration at the peculiar point 
with a lower content of water molecules. Some water molecules remain in the unclustered state.

At the peculiar point, the solution is completely clustered. In this state, water molecules are uniformly distributed around ethanol ones, what is natural from the thermodynamic viewpoint and corresponds to a uniform distribution of the substance over the system. In a vicinity of the peculiar point, unclustered molecules can appear only due to thermal fluctuations.

The degree of solution clustering can also be characterized by the volume fraction of clusters in the solution:

$$
x_{v}^{(c)}=\frac{v_{c}(1-x)}{v_{a}-\left[\frac{v_{a} Z_{w}}{k(x)}+v_{w}\left(1-Z_{w}\right)+v_{c} Z_{w}\right](1-x)} .
$$

In accordance with the aforesaid, this quantity can be regarded as the volume fraction of the third, i.e. "clustered", component in the solution. Figure 3 demonstrates the concentration dependences for the volume fraction of the clustered component in the solution at various temperatures. The calculations were carried out by formula (12). The exhibited data make it evident that the volume fraction of clusters monotonically decreases, as the temperature grows.

On the basis of the data of work [27] for the density of aqueous methanol solutions, in which the peculiar point was observed at $x=x_{p}=0.16$, we also calculated the corresponding quantity $Z_{w}$. In the calculations, formula (11) was used. The concentration dependences of the parameter $Z_{w}$ obtained for the methanol-water solutions are shown in Fig. 4. As in the case of ethanol-water solutions, the clustering degree of water molecules in the methanol-water solution decreases with the increasing temperature.

It should be mentioned that this approach was applied in work [28] to describe the volume effects in water-alcohol solutions. In the cited work, the solution was considered as a mixture of four components: pure water, pure alcohol, "solvates of nonpolar groups", and unclustered water molecules. A special attention was paid to the concentration dependence of the temperature, at which the water density had a maximum, and to the behavior of the partial molar volumes. However, this approach was applied within the interval $0<x<0.17$, so that the indicated dependences were not considered at high alcohol concentrations in the solution.

The authors of work [28] presented the following expression for the average molar volume of the solution:

$V_{s}=\frac{1}{n_{1}+n_{2}}\left[n_{1} V_{1}+n_{2} V_{2}+\sum_{i} n_{i} V_{i}\right]$

where $n_{k}$ and $V_{k}$ are the number of moles and the molar volume, respectively, of "pure" water $(k=1)$ and alcohol $(k=2)$; whereas $n_{i}$ and $V_{i}$ are the corresponding parameters for the complexes available in the solutions. In our consideration, we confined their number to only one type of complexes, namely, elementary clusters. The influence of other molecular formations on the solution volume will be a subject of the following works. In our view, only this restriction is responsible for the dependence of the parameter $k$ on the solution concentration.

\section{Conclusions}

The results of numerical simulation showed that, in the first approximation, the binary aqueous solutions of alcohols can be regarded as consisting of three components: alcohol, water, and clusters. The latter are formed, when the first two components are mixed (the clustered component). A mixture of those three components can be considered as an ideal solution. The clustering degree of water-alcohol solutions monotonically decreases from 1 to 0 , as the alcohol concentration increases from its value at the peculiar point to that of pure alcohol. Provided the same solution concentrations, the clustering degree increases, as the temperature decreases.

The authors express their deep gratitude to Academician of the National Academy of Sciences L.A. Bulavin for his permanent attention to our work, comprehensive assistance, inspiration, and stimulation. We are sincerely thankful to Prof. M.P. Malomuzh for the fruitful discussion of the results of this work and his assistance in writing the paper.

1. I. Prigogine. The Molecular Theory of Solutions (NorthHolland, 1957) [ISBN: 5-229-00473-8].

2. A.A. Tager, L.V. Adamova. The volumes of mixing of liquids and their importance for the modern theory of solutions. Russ. Chem. Rev. 49, 325 (1980). 
3. L.A. Bulavin, V.Ya. Gotsul'skii, N.P. Malomuzh, V.E. Chechko. Relaxation and equilibrium properties of dilute aqueous solutions of alcohols. Russ. Chem. Bull. Int. Edit. 65, 851, (2016).

4. M.F. Vuks. Light Scattering in Gases, Liquids, and Solutions (Leningrad State Univ., 1977) (in Russian).

5. M.F. Vuks, L.V. Shurupova. Light scattering by solutions of propyl alcohols in water and heavy water. Zh. Strukt. Khim. 12, 712 (1971) (in Russian).

6. G.W. Beer, D.J. Jolly. Comments on "The scattering of light and phase transition in solution of tertiary butyl alcohol in water". Opt. Commun. 11, 150 (1974).

7. L.V. Lanshina, A.I. Abramovich. The compressibility, molecular light scattering, and structure of alcoholic solutions of benzene. Russ. J. Phys. Chem. A 79, 608 (2005).

8. M.A. Anisimov. Critical Phenomena in Liquids and Liquid Crystals (Gordon and Breach, 1991).

9. D. Subramanian, J.B. Klauda, J. Leys, M.A. Anisimov. Thermodynamic anomalies and structural fluctuations in aqueous solutions of tertiary butyl alcohol. Vestn. SanktPeterburg. Univ. 4, 139 (2013).

10. E.S. Balankina. The influence of the size and packing of molecules on the volume-thermal properties of solutions. Russ. J. Phys. Chem. A 82, 1104 (2008).

11. E.S. Balankina. Theoretical Study of the Relationship "Packing Density-Thermodynamic Properties" in Condensed Systems. Dr. Sci. thesis (Tver' State Univ., 2010) (in Russian).

12. V.Ya. Gotsul'skii, N.P. Malomuzh, V.E. Chechko. Features of the temperature and concentration dependences of the contraction of aqueous solutions of ethanol. Russ. J. Phys. Chem. A 87, 1638 (2013).

13. V.Ya. Gotsul'skii, N.P. Malomuzh, M.V. Timofeev, V.E. Chechko. Contraction of aqueous solutions of monoatomic alcohols. Russ. J. Phys. Chem. A 89, 51 (2015)

14. V.Ya. Gotsulskiy, N.P. Malomuzh, V.E. Chechko. Particular points of water-alcohol solutions. Russ. J. Phys. Chem. A 89, 207 (2015).

15. D.I. Mendeleev. Solutions (Izd. Akad. Nauk SSSR, 1956) (in Russian).

16. Yu.I. Naberukhin, V.A. Rogov. The structure of aqueous non-electrolyte solutions (comparative analysis of the thermodynamic properties of aqueous and non-aqueous binary systems). Russ. Chem. Rev. 40, 207 (1971).

17. G. Scatchard. Change of volume on mixing and the equations for non-electrolyte mixtures. Trans. Faraday Soc. 33, 160 (1937).
18. N.P. Malomuzh, V.N. Makhlaichuk, P.V. Makhlaichuk, K.N. Pankratov. Cluster structure of water in accordance with the data on dielectric permittivity and heat capacity. J. Struct. Chem. 54, S205 (2013).

19. M.V. Timofeev. Model of compression of water-alcohol solutions. Zh. Fiz. Khim. 88, 1354 (2014) (in Russian).

20. Yu.I. Naberukhin, V.P. Voloshin. Distributions of hydrogen bond lifetimes in instantaneous and inherent structures of water. Z. Phys. Chem. 223, 1119 (2009).

21. G.G. Malenkov. Liquid water and ices: understanding the structure and physical properties. Condens. Matter 21, 283101 (2009).

22. V.P. Voloshin, Yu.I. Naberukhin, G.G. Malenkov. Percolation analysis of the network of hydrogen water connections: the dyeing of connections on time of life and energy. Struct. Dynam. Mol. Syst. 10, 12 (2011).

23. L.D. Landau, E.M. Lifshitz. Statistical Physics, Part 1 (Pergamon Press, 1980).

24. Tables for the Determination of the Content of Ethyl Alcohol in Water-Alcohol Solutions (Izd. Standartov, Moscow, 1972) (in Russian).

25. G.C. Pimentel, A.L. McClellan. The Hydrogen Bond (Freeman, 1960).

26. N.P. Malomuzh, E.L. Slinchak. The cluster structure of dilute aqueous-alcoholic solutions and molecular light scattering in them. Russ. J. Phys. Chem. A 81, 1777 (2007).

27. CRC Handbook of Chemistry and Physics (CRC, 1962).

28. I.N. Kochnev. Volume effects in alcohol-water solutions. In Molecular Physics and Biophysics of Aqueous Systems (Leningrad State Univ., 1972), Vol. 1, p. 19 (in Russian).

Received 21.02.18.

Translated from Ukrainian by O.I. Voitenko

В.Є. Чечко, В.Я. Гочулъский

ЯКІСНИЙ АНАЛІЗ КЛАСТЕРИЗАЦЇ̈

В СПИРТОВО-ВОДНИХ РОЗЧИНАХ

$\mathrm{P}$ е $з$ ю м е

У роботі обговорюються особливості кластеризації у водних розчинах одноатомних спиртів за концентрацій більших, ніж в особливій точці. Вона виникає внаслідок утворення водневих зв'язків між молекулами води і спирту, енергія яких дещо перевищує енергію водневих зв'язків між однотипними парами молекул вода-вода та спирт-спирт. Приймається, що у розчинах утворюються елементарні кластери, склад яких є фіксованим за концентрацій менших, ніж в особливій точці, і змінюється за певним законом праворуч від неї. Визначено ступінь кластеризації розчину як функцію його концентрації і температури. 